\title{
Simulating Electricity Consumption Pattern for Household Appliances using Demand Side Strategies - A Review
}

\author{
Patrick Ozoh \\ Department of Computer Science \\ University of Waikato \\ patrickozoh@yahoo.co.uk
}

\author{
Mark Apperley \\ Department of Computer Science \\ University of Waikato \\ mark.apperley@waikato.ac.nz
}

\begin{abstract}
This paper investigates research work related to the modelling and simulation of household electricity consumption with a view to developing a simulation to evaluate the effectiveness of demand-side management mechanisms. The eventual aim of the research is to be able to model household consumption down to the level of individual appliance use in order to explore and assess the impact of different demand-side strategies, both in individual household consumption, and on overall grid balance. The focus of this paper is to survey relevant research on simulation of household consumption, potential demand-side strategies and their impact, and modelling techniques for residential consumption. From this review, the paper provides a number of pointers for future effort in the area of modelling the impact of demand-side management strategies and techniques.
\end{abstract}

Keywords

Model, computer simulation, household consumption, demand-side management, electricity grid.

\section{INTRODUCTION}

Efficient control is often the most effective option to reduce energy costs in electricity consumption by household appliances. Using demand side strategies, customers are charged different rates during peak times and off-peak times. By moving load out of peak times, a client can avoid high electricity costs and thus realize savings on their electricity account. The focus of this paper is a review of research into the effectiveness of load matching and shifting techniques in demandside load management. Load matching in power system management consists of trying to dispatch the most favourable power sources to meet the load which is the total power of consumers' demand, while load shifting refers to moving generation capacity from one part of the grid to another resulting in fewer blackouts and eliminating over or under voltages. The aim of demand-side load management is to enable consumers to use less energy during peak hours and shift energy use to off-peak hours in order to improve energy use efficiency. This entails reduction of electricity costs to consumers, and there is the need to study the impact of load balancing and load shifting on the electricity grid. This research is also based on the necessity to simulate load profiles for consumers based on age, location and income, and description of consumption and cost benefits at appliance level. Due to the importance of having an efficient power management system, a number of studies have focused on the efficient utilization of electric appliances in households and industrial energy consumption. This research reviews papers on the simulation, identification, and the application of power utilization strategies at the appliance level in households.

Although there are many publications about applying demand side strategies to appliance use, and modelling their usage patterns, this paper seeks to understand the energy demands and usage patterns of

Permission to make digital or hard copies of all or part of this work for personal or classroom use is granted without fee provided that copies are not made or distributed for profit or commercial advantage and that copies bear this notice and the full citation on the first page. Copyrights for components of this work owned by others than ACM mustbe honored. Abstracting with credit is permitted. To copy otherwise, or republish, to post on servers or to redistribute to lists, requires prior specific permission and/or a fee. Request permissions fromPermissions@acm.org. CHINZ 2015, September 3-4, 2015, Hamilton, New Zealand

Copyright is held by the owner/author(s).

Publication rights licensed to ACM.

ACM 978-1-4503-3670-3/15/09 ..\$15.00

DOI: http://dx.doi.org/10.1145/2808047.2808057 household appliances using load shifting strategies. The growing demand for electricity consumption makes it imperative to use electric appliances in a more efficient manner by introducing load shifting and load matching to improve overall energy utilization. An analysis of the development of simulation models for electric appliances use, with respect to their ability to shift their energy demand, was discussed by Stadler et al. (2009). Results from this study indicate that household devices such as electric boilers, off-peak storage heaters, or freezers, are more suited to load balancing than a refrigerator. Moreau (2011) presented a control strategy for water heaters that minimized the consumption demand when the heating elements are reactivated at the end of a load shifting period initiated by utilities shifting hot water demand from peak hours to off-peak hours. The research indicated that the consumption demand of water heaters after such universal load shifting periods can be detrimental to the efficiency of the measure if not adequately controlled. A regression-based approach to quantify hourly baseline electric loads in a critical-peak pricing (CPP) experiment was presented by Herter and Wayland (2010). Based on results from this research, residential CPP is a promising strategy for achieving demand response goals. This strategy can be developed in the absence of automated controls in households.

Electricity is a vital source of energy in daily life, especially for household appliances, and hence, energy use efficiency can be achieved by applying demand side strategies to these devices. This can be beneficial to consumers in terms of reduction in energy costs, and to the electricity grid in terms of an optimal and efficient allocation of resources. (Sughnathi, 2012) suggests efficient use of household appliances involves the effective application of demand-side management techniques to decrease energy consumption and demand. This work proposed that demand-side management is the planning, implementation and monitoring of energy utilization activities carried out by electric utilities to influence energy demand in order to modify consumers' level and pattern of energy usage for improved efficiency of appliance use. It suggested that the technique has improved with technological advancements, manufacturing processes, and communication breakthroughs, resulting in better quality at lower costs, and promoting energy efficiency for sustainable development. Power consumption has been found to be closely linked to energy price, and consumer income, age, geographical location, etc., (Ministry of Economic Development, 2014), and for this reason, there is a need to investigate the impact of these factors on demand-side strategies.

In the literature, the contribution of demand-side management techniques in achieving efficiency in household appliance use has been discussed. Ullah et al. (2013) presented an overview of home appliance scheduling techniques to implement demand side management in a smart grid. In this research, residential load controlling techniques were employed for efficient consumption of electricity in homes and offices. The techniques used in the research reduced the energy consumption cost and consumers were encouraged to schedule their appliance use by load shifting methods. The contribution of demand side management (DSM) to increasing efficiency of the electricity system was presented by Strbac (2008). The techniques discussed by this paper include load shifting, direct control methods of turning off appliances for short periods of time, 
load limiting by deciding which appliances to postpone, and time-ofuse pricing. DSM can shift load from peak hours to off-peak hours in order to improve energy use efficiency.

In order to adapt consumer behaviour more effectively, by modelling their household appliance use, users need to understand how much energy different appliances consume. Such feedback is necessary for consumers to enable them to adjust their behaviour and conserve energy. There have been a number of studies involving the simulation of appliance use in households. A simulation model that generated household load profiles for a range of smart appliances was discussed by Gottwalt et al. (2011). This paper investigated household profiles under flat tariffs and simulated changes in these profiles with the introduction of smart appliances. Results from the study indicated that individual households can benefit from investment in smart appliances. The research indicated that smart appliances make the hourly residential load flexible, which can support the balancing of demand and supply in the electricity grid. Firth et al. (2008) focused on the study of electricity consumption in a sample of UK domestic buildings to identify trends in appliance energy use. This study introduced a series of new analysis techniques to improve understanding of domestic electricity use. A model to simulate residential electricity consumption was also presented by Muratori et al. (2013). This model considered occupancy, cold appliance use, heating, ventilation, air conditioning, lighting, and activity-related power consumption. Results from the study proposed energy demand patterns that capture variations, load fluctuations, and diversity between household configuration, location, and size. Yu, Kim, and Son (2013) investigated minimizing household electricity bills by formulating optimization methods which provide schedules or plans for home appliance usage. The performance of the proposed algorithm obtained from the optimization techniques was numerically analyzed by using real time-varying electricity pricings. Results from the study indicated that using these techniques, residential electricity bills can be reduced by $12.0 \%$ from a worst case scenario and peak hourly load can be reduced by $35.3 \%$. The use of smart systems for controlling power consumption in households is becoming increasing important for improved efficiency. Demand-side management measures coupled with pricing incentives will go a long way towards achieving efficiency in appliance use, (Muratori et al. 2013).

This paper reviews a range of research on the application of energy saving measures or control mechanisms to individual appliances, during peak and off-peak periods in order to minimize costs and also to decrease energy demand in the electricity network. This will provide an insight into the simulation of household energy consumption down to appliance level. It is intended that a fine-grained simulation be developed in order to model and assess the impact of a range of household demand-side load management techniques. These techniques are motivated by both the desire to reduce individual household costs and the need to provide better load balancing at the grid level, particularly to enable more effective integration of a higher proportion of renewable non-deterministic energy sources, i.e., consumption estimates of future energy sources that cannot be obtained from current estimates. The structure of the paper is as follows. Section 2 describes various models developed for power consumption of household appliances, including their behaviour, and the introduction of load shifting and balancing for efficient use of appliances. A comprehensive literature review is carried out in this section. Section 3 compares the attributes considered in this study, to investigate their impact on efficient use of energy; Section 4 presents conclusions drawn from this study, and their respective contribution to efficiency in energy use. In the final section, recommendations from this study are set out.

\section{POWER CONSUMPTION ATTRIBUTES OF APPLIANCES}

In order to simulate household appliance use patterns, for the investigation of demand-side strategies, power consumption models have been developed. Power consumption models can be classified into dynamic or multivariate, because they are time-dependent. Dynamic consumption models are deterministic, i.e., future consumption estimates follow from current estimates; while multivariate consumption models use past data to estimate consumption. Several published studies have been selected here for detailed analysis, covering a good part of the available literature, and focusing on households, since the power consumption patterns vary more widely. (Raaij, 2014), (Siero, Bakker, and Dekker, 1996). Section 2.1 reviews research aimed at producing models of individual appliance usage based on time of day and occupancy. Section 2.2 discusses the impact of demand-side strategies on the electricity grid. In Section 2.3, literature on activity profile measurements for appliance use is discussed.

\section{Modelling Appliance Behaviour}

A process of simulation to evaluate the effectiveness of demand-side management techniques is considered by Bajada, Fox, and Long (2013). Their research models the integration of stochastic processes for residential electricity demand into the generation of fine-grained events. In the research, a Markov modulated on-off process is used to model each appliance within a household. This approach allows the utilization of time-use data obtained from surveys to perform the simulation. The model utilizes a standard Markov process to represent the active (on) and inactive (off) states of an appliance, as shown in Figure 1. The transition probabilities are derived from real data, and vary according to time of day.

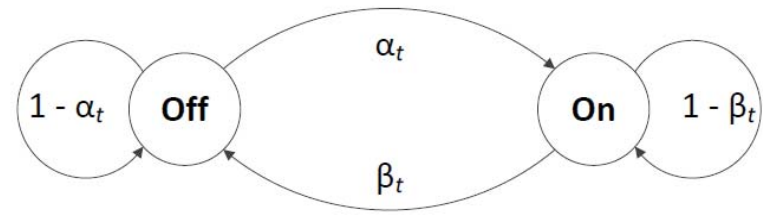

Figure1. Non-homogenous Markov on-off process (Bajada, Fox, and Long, 2013)

A simulation framework that utilizes Markov model is developed in the research. It supports a plug-in mechanism through which demand control policies can be integrated into the system such that the effects and performance of demand-side management strategies can be evaluated. It is designed to generate load profiles for thousands of households. The system allows the user to setup different households and appliance profiles, together with their respective quantities. In this research, households are grouped into categories that determine available appliances and their corresponding usage profiles, by indicating how often same appliance in a household is used. This allows different usage profiles to be associated with the same appliance type. The paper also grouped households under consumption policies. The simulation framework is designed to support multiple concurrent policy implementations that manage energy consumption using different criteria. The user can configure how many households should be simulated under each policy. Results from modelling household load data indicate that simulated aggregate load curves exhibit significant similarities to the average hourly load, as reported in a household electricity survey conducted in the UK.

In order to investigate demand side management issues, LópezRodríguez, Santiago, Trillo-Montero, and Torriti (2013) carried out a study of the occupancy pattern of energy consumption in Spanish properties. The main source of data for this research was the 20092010 Spanish TUS (Time Use Survey, 2009-2010). The survey identified three peaks in active occupancy, which coincide with morning, noon and evening. A stochastic model based on Markov chain Monte Carlo techniques was derived from the survey data. Each person in the household can be in either of two states: state 0 , called inactive, which defines a person who is either outside the household or 
at home but sleeping; or state 1, called active, in which the person is at home and awake. The research analyzed active occupancy, determined in time intervals in which occupancy peaks take place. The generated profiles in the study were used to model domestic electricity consumption, which enabled the identification of appliances that were in use during occupancy.

A study presenting a model framework for a stochastic generation of high-resolution series of time-resolved data on occupant's behaviour was carried out by Widén and Wäckelgård (2010) . It uses a Markovchain model to simulate demand data for synthetic occupancy patterns in households. The model assumes that a person in the household performs $\mathrm{t}$ activities in every discrete time step $\mathrm{k}=1, \ldots, N_{k}$. When time proceeds from $\mathrm{k}$ to $\mathrm{k}+1$, there is a transition probability $p_{i j}(k)$ of going from state $\mathrm{i}$ to $\mathrm{j}$. This includes the probability $p_{i i}(k)$ of staying in state $\mathrm{i}$. All $\mathrm{N}$ transitions between time steps $\mathrm{k}$ and $\mathrm{k}+1$ are examined and the total number $n_{i j}(k)$ of transitions between states $\mathrm{i}$ and $\mathrm{j}$ is determined. The load factor varies between zero and one, a low value is an indicator of high power variations, as the maximum power is high compared to the mean value. Conversely, a high value indicates a smooth demand and low variations. A detailed validation of the simulation of empirical time-use data for a set of activities over time against measurements show that modelled power demand data for individual households, as well as well as aggregate demand for an arbitrary number of households, have highly realistic patterns, in terms of end-use composition, diversity between households, short timescale fluctuations and load coincidence. The research suggests that the Markov-chain model produces activity patterns that realistically reproduce a spread of different end-use loads over time.

Ferreira, Cavalcante, and Fontes (2013) presented a pattern recognition method based on a systematic extraction of features, capable of recognizing consumption patterns in the electricity sector. The technique comprises two phases:

The first phase carries out pattern recognition through successive iterations. At the end of this phase, patterns or types associated with load curves are recognized.

The second phase considers only the patterns of each group, and defines the final groups associating each database (load curve) to one of the patterns recognized in the first phase.

Results obtained by the pattern recognition technique were compared to a method used in clustering; the Fuzzy C-method (FCM), and this revealed that the method generates conclusions consistent with reality, which supports the implementation of efficiency actions based on realistic features within the consumer market. The application of the pattern recognition method was able to recognize the existence of three patterns or demand profiles. By comparison, the FCM method was able to recognize two patterns. The third pattern represents a demand profile with lower energy consumption. The global silhouette index (GSI) is used to measure the clustering quality of energy demand profiles. This index measures the cohesion within, and differences between the clusters, regardless of the clustering technique used. The analysis is performed by clustering of the whole sample data (load curves from the database) based on statistical tests associated with the consumption profile, whereby clusters of load curves are obtained. From analysis carried out in the study, the quality of clustering obtained with the FCM method was slightly lower according to the GSI obtained (GSI equal to 0.25 and 0.28 for FCM and pattern recognition methods respectively).

Another study examines the relationship between residential electricity consumption and subdivision design characteristics, while controlling for the influence of a range of important covariates (Wilson, 2013). Summer, winter and annual electricity consumption was modelled for households, as a function of climate, demographic, structural, technological, behavioural and urban form factors using regression analysis. Control variables were derived from household surveys, spatial datasets and other sources. Linear regression models used in the study allowed for intra-group correlation, rather than assuming that observations within the sub-divisions were independent. The results of the regression analyses suggest that the most consistent predictors of household electricity usage are climate degree days, household size, number of bedrooms, and the nature of heating equipment. The research indicates that households tend to consume more electricity in the winter, particularly when the number of heating degree days is higher than average.

\section{Load Shifting and Balancing}

A study by Rosin et al. (2010) analyzed household high and low tariff electricity consumption based on workday and holiday loads. The authors investigated saving possibilities by shifting discretionary loads from high-tariff to low- tariff periods. It also considered high energy saving by using presence sensors and energy-efficient light bulbs. From the study, it is suggested that high- tariff energy consumption on workdays can be reduced from $78 \%$ to $53 \%$ of the total load, by load shifting and the use of energy efficient bulbs, while the total hightariff energy consumption can be reduced from $48 \%$ to $38 \%$. Overall total energy consumption is reduced to $56 \%$. This research indicates households with higher energy consumption or with more storage capacity integrated to the system have greater saving possibilities and that investments in more efficient systems are not justified if the lifetime of household appliances are equal to or shorter than the savings. The study suggest that small investments such as energyefficient bulbs, timers or presence sensors are profitable within 1-2 years, but that with existing tariff systems, there is little justification for the expense of a power management system for load scheduling and shifting.

A study to design, implement and evaluate the performance of a power consumption scheduler was reported by Lee, Kim, and Park (2012). This work is aimed at reducing the peak load in smart grid homes, with a power scheduler designed to reduce cost by reduction of energy consumption during peak demand time. The power scheduler is a networked appliance which interacts between utility companies, home appliances, and monitoring devices, (Figure 2).

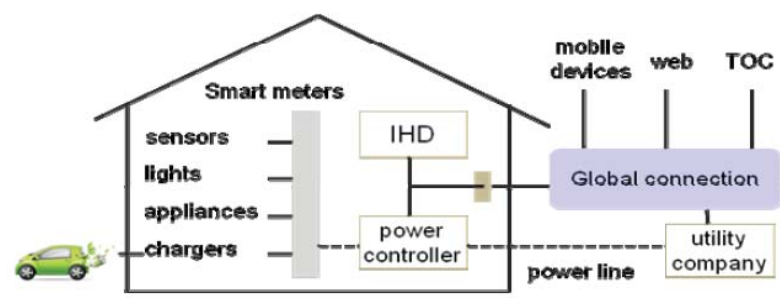

Figure 2: Power scheduler operation, (reproduced from Lee, Kim, and Park, 2012)

In this study, the controller exchanges information on price and demand with the utility company via the internet or a cellular network. The utility company sends a residential load change to the consumer's home, activating load control, demand response, and price adjustment. The controller then interacts with home appliances through a home area network, e.g. through a power line communication, measuring appliances' power consumption. Finally, the controller sends a message to the In-home display (IHD) to pass on information about specific events and price changes. The Total Operation Centre (TOC) interacts with respective in-home controllers through a global connection. The implementation of the power scheduler showed that the scheme was able to reduce peak load by up to $23.1 \%$, compared with previous scheduling methods. Additionally, in terms of peak reduction, the proposed scheme reduced the global peak by $16 \%$ for 
the home-scale scheduling unit where the number of appliances was generally fewer than 10 .

The use of fuzzy logic systems to model human behaviour related to activation of appliances and lighting at home was presented by Zuniga, and Castilla (2014). This work aimed to contribute to the study of demand-side system in seeking to reduce and/or shift the peaks present in the load curve, by constructing a system that was capable of mirroring the behaviour of the electrical distribution and consumption system. The system would be able to simulate the effects of different demand control strategies. In defining the rules governing the Fuzzy logic technique by the study, let A and B be inputs to the system and $\mathrm{C}$ the output. If $\mathrm{A}$ is high and $\mathrm{B}$ is very low, then $\mathrm{C}$ is medium. The authors calculated the hourly activation profile for each appliance and the load curve of the residential sector was also computed.

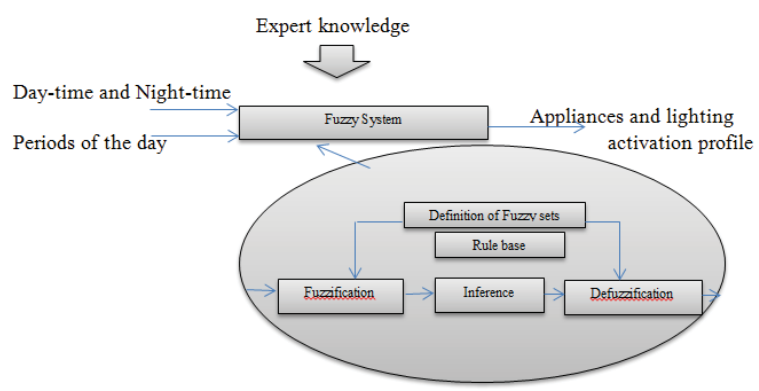

Figure 3. Fuzzy logic systems function diagram (reproduced from Zuniga and Castilla 2014)

The results from the study were obtained using fuzzy logic, which is based on how human behaviour affects the use of household appliances. The demand-side management strategy for the research was implemented by classifying household appliances based on their energy rating.

Another fuzzy logic interface system (FIS) to model household electrical consumption was presented by Ciabattoni et al. (2013), which uses as inputs, patterns of occupancy- when people are at home and awake, and typical domestic habits (i.e. activating specific applications). This model is designed to simulate electrical consumption for each different household from typical appliance patterns. It can be adapted to an individual household, with the possibility of adding any kind of appliance to the model, while existing appliances can be customized. The knowledge base covers electricity consumption for all appliances in the study. A fuzzification interface transforms collected input to the system, into fuzzy values. A deffuzification interface computes output values. Results from the study show good performance in simulating the consumption behaviour of the households, in relation to measured data, with plausible patterns of use.

\section{Gathering Data for Household Appliances}

Santiago et al. (2013) investigated energy losses and the economic consequences and implications of the use of small appliances and electronic devices in the residential sector. Measurements of different types of household appliances available in the database obtained from time use surveys were utilized, and the active and non-active annual power demands of these appliances in residences were determined. An estimation process of active power consumption in the residential sector by commonly used audio-visual (AV) equipment was carried out, by obtaining an individual standard model for each. The study was able to identify the contributions of individual devices to overall electricity consumption. In the research, even though the individual consumption of AV devices is very small, their use at an aggregated level for some hours per day leads to highly significant values for energy demand. This suggests that any measurement taken to reduce energy consumption in homes should not only consider major appliances, but also the combined contribution of these small appliances. Although a single AV device has an almost negligible contribution, the aggregated actions of this type of appliances, whose total annual energy demand is greater than $4000 \mathrm{GWh}$, can be significant enough to be taken into account in any energy efficiency program.

A study that presents a high-resolution model of domestic electricity use based on patterns of active occupancy (i.e. when people are at home and awake), and daily activity profiles that characterize how people spend their time performing certain activities is discussed by Richardson et al. (2010).

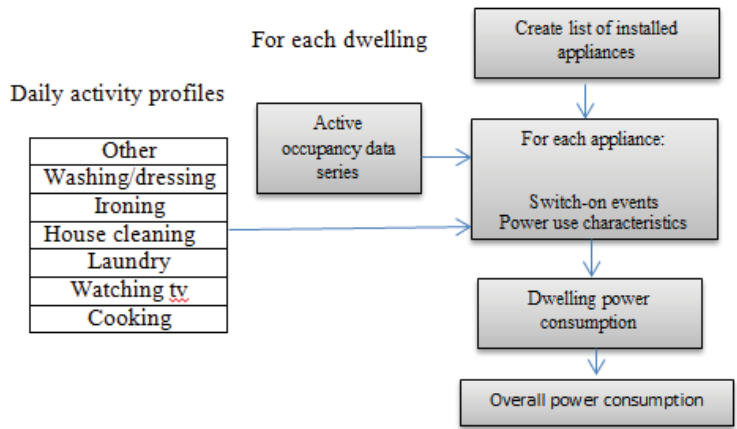

Figure 4: Electricity demand model architecture (Richardson et al., 2010)

These authors suggest that appliance used within a dwelling is naturally related to the number of people who are at home and awake. This time is referred to as "active occupancy" and it is represented for each dwelling within the model, as an integer that varies throughout the day in a pseudo random fashion, reflecting the natural behaviour of real people going about their daily lives. In order to refine the modelling of the timing of electricity demand, a second mechanism, based on the occupants' activities, is used. The research assigns an activity profile to each appliance in the model; hence the varying likelihood of the appliance being used throughout the day can be taken into account in a stochastic simulation. Electricity demand data was recorded at 22 domestic dwellings around the town of Loughborough in the East Midlands, UK, recorded at a 1-min interval. The measured data was used extensively to validate the model by way of a comprehensive comparison of the statistical characteristics of the synthetic and measured data. The purpose of the validation was to make more formal statistical comparisons between the measured and synthetic data. To this end, the model was used to create synthetic data for households covering a full year at 1 -min resolution. From results obtained from the study, synthetic data compares very well with the measured data and thus the model appears particularly good at representing the time-coincidence/diversity of demand between multiple dwellings.

\section{POWER CONSUMPTION OF APPLIANCES}

The important attributes of the three major issues considered in this study affecting power consumption behaviour for household appliances are listed in Table 1. These are modelling appliances behaviour; load shifting and balancing; and gathering data for household appliances. These issues are investigated for occupants' behaviour in using electric appliances, leading to the identification of behaviours and end-uses which bring about efficient power consumption for these appliances. The strengths and weaknesses of the issues under study are examined to determine their impact on efficient energy use. 
Table 1: Positive and negative attributes of approaches to power consumption techniques in households

\begin{tabular}{|c|c|c|c|}
\hline Attributes & Issues & Positive attributes & Negative attributes \\
\hline \multirow[t]{17}{*}{ Modelling appliance behaviour } & \multirow[t]{3}{*}{ Bajada, Fox, and Long, 2013} & $\begin{array}{l}\text { Determination of power consumption } \\
\text { at appliance level based on simulation }\end{array}$ & Reliant on historical data \\
\hline & & $\begin{array}{l}\text { Enables evaluation of demand-side } \\
\text { strategies }\end{array}$ & $\begin{array}{l}\text { Model only supports a two-way } \\
\text { process }\end{array}$ \\
\hline & & $\begin{array}{l}\text { Impact on consumption based on } \\
\text { occupancy }\end{array}$ & \\
\hline & \multirow{3}{*}{$\begin{array}{l}\text { Lopez-Rodriguez, Santiago, Trillo- } \\
\text { Montero, Torriti, } 2013\end{array}$} & Enables load shifting and balancing & Reliant on historical data \\
\hline & & $\begin{array}{l}\text { Number and activities of occupants in } \\
\text { a household are known }\end{array}$ & $\begin{array}{l}\text { Investigates household profiles during } \\
\text { peak periods }\end{array}$ \\
\hline & & $\begin{array}{l}\text { Does not differentiate between active } \\
\text { and inactive occupancy or location }\end{array}$ & $\begin{array}{l}\text { Does not differentiate between active } \\
\text { and inactive occupancy or location }\end{array}$ \\
\hline & \multirow[t]{4}{*}{ Widen, Joakim, \&Wackelgard, 2010} & $\begin{array}{l}\text { Presents electricity demand based on } \\
\text { occupancy state }\end{array}$ & Model based only on location \\
\hline & & Simple input data & \\
\hline & & $\begin{array}{l}\text { Possible to adjust model to more } \\
\text { specific cases }\end{array}$ & \\
\hline & & $\begin{array}{l}\text { Investigates effects of load profiles of } \\
\text { different appliances on electricity use }\end{array}$ & \\
\hline & \multirow[t]{3}{*}{ Ferrira, Cavalcante, Fontes, 2013} & $\begin{array}{l}\text { Investigates multiple variables } \\
\text { affecting household consumption } \\
\text { profile }\end{array}$ & Model based only on location \\
\hline & & Discusses trends & \\
\hline & & $\begin{array}{l}\text { Study is implemented in different } \\
\text { towns }\end{array}$ & \\
\hline & \multirow[t]{4}{*}{ Wilson, 2013} & $\begin{array}{l}\text { Determination of electricity } \\
\text { consumption modelled by climate, } \\
\text { demographic, behavioural, } \\
\text { technological, and urban factors }\end{array}$ & $\begin{array}{l}\text { No explicit description of consumption } \\
\text { at appliance level }\end{array}$ \\
\hline & & Models new technology & Relies on historical consumption data \\
\hline & & Encompasses trends & $\begin{array}{l}\text { Lack of information on household unit } \\
\text { size }\end{array}$ \\
\hline & & & Generalization of prices in models \\
\hline \multirow[t]{14}{*}{ Load shifting and balancing } & \multirow[t]{3}{*}{ Rosin et al., 2010} & Inclusion of economic benefits & $\begin{array}{l}\text { The study considers just one } \\
\text { household }\end{array}$ \\
\hline & & Discusses load shifting & \\
\hline & & Number of occupants is considered & \\
\hline & \multirow[t]{3}{*}{ Lee, Kim, Park, 2012} & $\begin{array}{l}\text { Implements a power scheduling } \\
\text { scheme }\end{array}$ & $\begin{array}{l}\text { Does not consider individual } \\
\text { appliances }\end{array}$ \\
\hline & & $\begin{array}{l}\text { Introduces automated technology for } \\
\text { control }\end{array}$ & $\begin{array}{l}\text { Does not incorporate real-time price } \\
\text { change }\end{array}$ \\
\hline & & Utilizes demand-side strategies & $\begin{array}{l}\text { Does not specify power requirements } \\
\text { for both sellers and consumers }\end{array}$ \\
\hline & \multirow[t]{4}{*}{ Zuniga, Castilla, 2014} & Reduces/shifts the peak in loads & Relies mainly on human behaviour \\
\hline & & $\begin{array}{l}\text { Mirrors the behaviour of electrical } \\
\text { distribution and consumption system } \\
\text { based on simulation }\end{array}$ & Relies on historical data \\
\hline & & Encompasses occupant behaviour & \\
\hline & & $\begin{array}{l}\text { Obtains household hourly profile } \\
\text { based on individual appliances }\end{array}$ & \\
\hline & \multirow[t]{4}{*}{ Ciabattoni et. al., 2013} & $\begin{array}{l}\text { Model us adaptable to any household } \\
\text { or appliance }\end{array}$ & $\begin{array}{l}\text { Need to be replicated in other } \\
\text { regions/towns }\end{array}$ \\
\hline & & $\begin{array}{l}\text { Profile shows when appliances are } \\
\text { been used or not }\end{array}$ & \\
\hline & & $\begin{array}{l}\text { Determination of energy use behaviour } \\
\text { based on simulation }\end{array}$ & \\
\hline & & Utilizes real-time data & \\
\hline \multirow[t]{7}{*}{$\begin{array}{l}\text { Gathering data for household } \\
\text { appliances }\end{array}$} & \multirow[t]{3}{*}{ Santiago et al., 2013} & $\begin{array}{l}\text { Measures individual household } \\
\text { appliances }\end{array}$ & Utilizes historical data \\
\hline & & $\begin{array}{l}\text { Determines whether appliance is active } \\
\text { or not }\end{array}$ & Does not cover a typical household \\
\hline & & $\begin{array}{l}\text { Indicates that small appliances } \\
\text { contribute to energy savings }\end{array}$ & \\
\hline & \multirow[t]{4}{*}{ Richardson et al., 2010} & Incorporates daily activity profile & $\begin{array}{l}\text { Small and large transitions in time are } \\
\text { under-represented in the model }\end{array}$ \\
\hline & & Utilizes real-time data & $\begin{array}{l}\text { Model does not represent those that are } \\
\text { inactive }\end{array}$ \\
\hline & & $\begin{array}{l}\text { Determination of one-minute } \\
\text { electricity demand based on simulation }\end{array}$ & $\begin{array}{l}\text { The need to include socio-economic } \\
\text { factors and individual attributes }\end{array}$ \\
\hline & & & $\begin{array}{l}\text { Model under-represents seasonal } \\
\text { variation of electricity demand }\end{array}$ \\
\hline
\end{tabular}




\section{CONCLUSION}

Demand side Management will play an increasingly important role; so that work on modelling power consumption behaviour is very necessary. Obtaining power consumption models is the premise and basis of predicting power consumption pattern for individual household appliances. The problems and research directions are as follows:

1) There is a need to simulate household consumption patterns for electric devices in order to model demand-side management.

2) The study of simulating trends from household electricity consumption. The need to study residential electricity consumption based on income, age and geographical location.

3) The study of the impact of small domestic electronic devices on efficient electricity usage.

4) The study of the extent to which energy saving electric devices use may outweigh other methods

5) The study of the scope and nature of change in energy use behaviour. Identifying household activity profiles throughout the day, not only during peaks. This will include differentiating these activities and active occupancy profiles depending on different regions where households are located.

\section{RECOMMENDATIONS}

Many demand-side management problems, such as simulation of power consumption for households, are related to energy use behaviour and interventions in energy use practices. Considering previous reviews on simulation of power consumption for household appliances (e.g. (Zhou, Yang, and Shen 2013)), this paper reveals similarities and differences, such as the pattern of consumption for household appliances. The previous research carried out has already pointed out issues for improvement. Taken together, these reviewed studies have added to our understanding of how to model power consumption for household appliances using the techniques mentioned in this study.

It is important to recommend some factors contributing to household energy use. Such factors as consumer behaviour, income, age, geographical location, have an effect on power consumption for household appliances. In terms of improving efficiency of appliance use in households, it is important to identify target behaviours that have a relatively large energy saving potential. By keeping efficiency in use of household appliances in mind, researchers can focus on consumer behaviour that significantly influences appliance efficiency use qualities.

Most studies reveal only the extent of effects on the electricity network, without providing insight into the reasons why. In other words, the effectiveness of the strategy on the electricity grid and possible determinants of demand-side management measures should be examined simultaneously. A thorough monitoring of appliance use and energy-savings may increase the understanding of the effect on the electricity network. The guidelines proposed in this study may help in providing more efficient use of household appliances. The study will also lead to understanding the benefits achievable from applying demand-side management measures as they relate to the energy grid.

\section{REFERENCES}

1. A. Ferreira, C. Cavalcante, C. Fontes, J. Marambio. 2013 "A New Method for Pattern Recognition in Load Profiles to Support Decision-Making in the Management of the Electric Sector." Electrical Power and Energy Systems 53: 824-31.
2. Bajada, Josef, Maria Fox, and Derek Long. 2013. "Load Modelling and Simulation of Household Electricity Consumption for the Evaluation of Demand-Side Management Strategies." IEEE PES ISGT Europe 2013: 15.

http://ieeexplore.ieee.org/lpdocs/epic03/wrapper.htm?arnu mber $=6695250$.

3. Ciabattoni, Lucio, Massimo Grisostomi, Gianluca Ippoliti, and Sauro Longhi. 2013. "A Fuzzy Logic Tool for Household Electrical Consumption Modeling." IECON 2013 - 39th Annual Conference of the IEEE Industrial Electronics Society: 8022-27.

http://ieeexplore.ieee.org/lpdocs/epic03/wrapper.htm?arnu mber $=6700474$.

4. F. Siero, A. Bakker, G. Dekker, M. Burg. 1996. "Changing Organizational Energy Consumption Behaviour through Comparative Feedback." Journal of Environmental Psychology 16: 235-46.

5. F. Van Raaij, J. Van Houwelingen. 2014. "The Effect of on and In-Home Daily Energy Use Electronic Feedback." JSTOR 16(1): 98-105.

6. Firth, S., K. Lomas, a. Wright, and R. Wall. 2008.

"Identifying Trends in the Use of Domestic Appliances from Household Electricity Consumption Measurements." Energy and Buildings 40(5): 926-36. http://linkinghub.elsevier.com/retrieve/pii/S0378778807002 022 (March 24, 2014).

7. Gottwalt, Sebastian, Wolfgang Ketter, Carsten Block, John Collins, and Christof Weinhardt. 2011. "Demand Side management-A Simulation of Household Behavior under Variable Prices." Energy Policy 39(12): 8163-74. http://linkinghub.elsevier.com/retrieve/pii/S0301421511008 007 (March 19, 2014).

8. Herter, Karen, and Seth Wayland. 2010. "Residential Response to Critical-Peak Pricing of Electricity: California Evidence." Energy 35(4): 1561-67. http://linkinghub.elsevier.com/retrieve/pii/S0360544209003 016 (August 12, 2014)

9. J. Lee, H. Kim, G. Park, M. Kang. 2012. "Energy Consumption Scheduler for Demand Response Systems in the Smart Grid *." 969: 955-69.

10. K.V. Zuniga, I. Castilla, R.M. Aguilar. 2014. "Using Fuzzy Logic to Model the Behavior of Residential Electrical Utility Customers." Applied Energy 115: 384-93.

11. L. Sughnathi, S. Anand. 2012. "Energy Models for Demand Forecasting - A Review." Renewable and Sustainable Energy Reviews 16: 1223-40.

12. M. López-Rodríguez, I. Santiago, D. Trillo-Montero, J. Torriti, A. Moreno-Munoz. 2013. "Analysis and Modeling of Active Occupancy of the Residential Sector in Spain: An Indicator of Residential Electricity Consumption." Energy Policy 62: 742-51.

13. Ministry of Economic Development. 2014. Electricity.

14. Moreau, Alain. 2011. "Control Strategy for Domestic Water Heaters during Peak Periods and Its Impact on the Demand for Electricity." Energy Procedia 12: 1074-82. http://linkinghub.elsevier.com/retrieve/pii/S1876610211019 667 (August 14, 2014).

15. Muratori, Matteo, Matthew C. Roberts, Ramteen Sioshansi, Vincenzo Marano, and Giorgio Rizzoni. 2013. "A Highly Resolved Modeling Technique to Simulate Residential Power Demand." Applied Energy 107: 465-73. http://linkinghub.elsevier.com/retrieve/pii/S0306261913001 $75 \mathrm{X}$.

16. Richardson, Ian, Murray Thomson, David Infield, and Conor Clifford. 2010. "Domestic Electricity Use: A HighResolution Energy Demand Model." Energy and Buildings 
42(10): $1878-87$.

http://linkinghub.elsevier.com/retrieve/pii/S0378778810001 854 (May 26, 2014).

17. Rosin, Argo, Taavi Möller, Madis Lehtla, and Hardi Hõimoja. 2010. "Analysis of Household Electricity Consumption Patterns and Economy of Water Heating Shifting and Saving Bulbs." Power and Electrical Engineering 26(1): 15-20.

18. Santiago, I., M.a. López-Rodríguez, a. Gil-de-Castro, a. Moreno-Munoz, and J.J. Luna-Rodríguez. 2013. "Energy Consumption of Audiovisual Devices in the Residential Sector: Economic Impact of Harmonic Losses." Energy 60: 292-301.

http://linkinghub.elsevier.com/retrieve/pii/S0360544213006 932 (May 27, 2014)

19. Stadler, Michael, Wolfram Krause, Michael Sonnenschein, and Ute Vogel. 2009. "Modelling and Evaluation of Control Schemes for Enhancing Load Shift of Electricity Demand for Cooling Devices." Environmental Modelling \& Software 24(2): 285-95.

http://linkinghub.elsevier.com/retrieve/pii/S136481520800 321 (August 14, 2014)

http://linkinghub.elsevier.com/retrieve/pii/S01692046130 00601 (May 26, 2014)

24. Yu, Taeyoon, Dong Sik Kim, and Sung-yong Son. 2013. "Home Appliance Scheduling Optimization with TimeVarying Electricity Price and Peak Load Limitation." International Journal of Smart Home 23: 196-99.

25. Zhou, Kai-le, Shan-lin Yang, and Chao Shen. 2013. "A Review of Electric Load Classification in Smart Grid Environment." Renewable and Sustainable Energy Reviews 24: 103-10. http://linkinghub.elsevier.com/retrieve/pii/S13640321130 01822 (May 27, 2014)
20. Strbac, Goran. 2008. "Demand Side Management: Benefits and Challenges." Energy Policy 36(12): 4419-26. http://linkinghub.elsevier.com/retrieve/pii/S0301421508004 606 (January 26, 2014).

21. Ullah, M.N., N. Javaid, I. Khan, a. Mahmood, and M.U. Farooq. 2013. "Residential Energy Consumption Controlling Techniques to Enable Autonomous Demand Side Management in Future Smart Grid Communications." 2013 Eighth International Conference on Broadband and Wireless Computing, Communication and Applications: $545-50$. http://ieeexplore.ieee.org/lpdocs/epic03/wrapper.htm?arnu mber $=6690944$ (July 14, 2014).

22. Widén, Joakim, and Ewa Wäckelgård. 2010. "A HighResolution Stochastic Model of Domestic Activity Patterns and Electricity Demand." Applied Energy 87(6): 1880-92. http://linkinghub.elsevier.com/retrieve/pii/S0306261909004 930 (May 27, 2014).

23. Wilson, Bev. 2013. "Urban Form and Residential Electricity Consumption: Evidence from Illinois, USA." Landscape and Urban Planning 115: 62-71. 